\title{
Exílios índios: sobre deslocamentos compulsórios no período militar (1964-1988)1
}

\section{Edilene Coffaci de Lima Professora do Departamento de Antropologia da UFPR Pesquisadora PQ2 - CNPq}

Resumo: Neste artigo irei tratar de alguns deslocamentos compulsórios de populações indígenas que se deram no período militar, particularmente nos primeiros anos da década de 1970. A partir de pesquisa bibliográfica e documental discorrerei mais longamente sobre três casos que me parecem emblemáticos da violência perpetrada naquele período: são os casos dos Xetá, dos Tapayuna e dos Ofaié-Xavante. O lema "integrar para não entregar", vigente no período militar, mais que um jogo de palavras, supunha a expansão das frentes de colonização que, inevitavelmente, alcançavam os índios em duplo (e dúbio) sentido.

Palavras-chave: deslocamentos compulsórios; período militar; Xetá; Tapayuna; Ofaié.

\footnotetext{
${ }^{1}$ Uma primeira versão deste texto foi apresentada no GT Transformações do espaço ameríndio na América do Sul, na XI Reunião de Antropologia do Mercosul, que teve lugar em Montevidéu, em dezembro de 2015. Em 07 de outubro de 2016 apresentei uma nova versão no seminário Cesta Intempestiva, promovido Centro de Estudos Ameríndios (Cesta) da Universidade de São Paulo, como parte da conclusão de meu período de pós-doutoramento naquela instituição em 2015. Agradeço aos colegas presentes o estimulante debate, a partir do qual tentei incorporar as críticas e sugestões, definindo a versão que agora apresento, eximindo-os de toda responsabilidade pelas insuficiências persistentes.
} 


\title{
Indian Exiles: \\ On compulsory displacements in the military period \\ (1964-1988)
}

\begin{abstract}
In this paper I will deal with some compulsory displacements of indigenous populations that occurred during the military period, particularly in the early 70's. Based on bibliographic and documentary research, I will discourse more about three cases that seem to me emblematic violence perpetrated during that period. The three cases are: Xetá, Tapayuna and OfaiéXavante. The motto "integrate to not hand over", present in the dictatorial period, supposed the expansion of the colonization fronts that, inevitably, achieved the Indians in double (and dubious) meaning.
\end{abstract}

Ofaie.

Keywords: displacement compulsory; military period; Xeta; Tapayuna;

\section{Indios exiliados: sobre el desplazamiento forzado en el período military (1964-1988)}

Resúmen: En este artigo trato sobre algunos desplazamientos forzosos de poblaciones indígenas que ocurrieron durante el periodo de la dictadura militar, especialmente durante los primeros años de la década de 1970. A partir de una investigación bibliográfica y documental analizaré detenidamente tres casos que me parecen emblemáticos de la violencia perpetrada durante aquel periodo: se trata de los casos de los Xetá, de los Tapayuna y de los Ofaié-Xaxante. El lema "integrar para no entregar", vigente durante el periodo militar, más que un juego de palabras implicaba la expansión de los frentes de colonización que, inevitablemente, alcanzaban a los indios en un doble (y dudoso) sentido.

Palabras clave: desplazamientos forzosos, dictadura militar, Xetá, Tapayuna, Ofaié. 


\author{
O exílio, ao contrário do nacionalismo, é \\ fundamentalmente um estado de ser \\ descontínuo. Os exilados estão separados das \\ raízes, da terra natal, do passado. \\ (Edward Said, 2003:50)
}

Não há qualquer dúvida de que sabemos hoje sobre a história dos índios no Brasil bem mais do que há pouco tempo atrás, não só porque aumentou significativamente o número de antropólogos e historiadores, entre outros pesquisadores, dedicados à temática, mas porque nas últimas décadas um impulso foi dado à história indígena. É preciso indicar, contudo, que esse impulso está mais concentrado nos períodos colonial e imperial. E tal lacuna é tão expressiva que faz com que talvez possamos falar sem muito pudor que hoje conhecemos um tanto mais sobre o que se passou com os índios no período colonial e no Império que sobre anos recentes. Sabemos menos ainda, se quisermos insistir, sobre os últimos 50 anos, o que inevitavelmente abrange não só o período republicano, mas particularmente o período militar. Não que se deva valorar positivamente mais um período do que outro - como se a história recente devesse sobrepujar épocas mais remotas - mas, reconhecendo o valor de ambas, garantir que, com o conhecimento de fatos que aconteceram há pouco, mas ocultos dos olhos de todos, se possa reparar a memória daqueles que ainda estão vivos, que conseguiram resistir a toda sorte de intempéries. A recente divulgação do relatório da Comissão Nacional da Verdade (CNV) permitiu mostrar o quão pouco conhecemos.

Os anos 70 do século passado, sob comando militar, são marcados pela insígnia do "progresso" - de gigantescos investimentos em infraestrutura e em prospecção mineral -, como escreveu Carneiro da Cunha (1992) na introdução de um compêndio sobre história indígena2. A ambição militar do "progresso" marca aquela década, a qual fez inúmeras "vítimas", de norte a sul do país, como intitulou seu livro Shelton Davis ao tratar do mesmo período.

Nosso pouco conhecimento da história indígena recente, contudo, não deve ser creditado exclusivamente ao desconhecimento dos documentos escritos, pois são relativamente próximas as queixas de colegas que reclamam a ausência de estudos sobre a história e a presença indígena em outras áreas de pesquisa que não a Antropologia. De forma impaciente, escreveu John Monteiro em meados da década de 1990: "a historiografia brasileira tem sido cúmplice na tentativa de erradicar os índios" (1994:10). Uma queixa que, com outras palavras, se repete também no trabalho de Egon Heck (1996), ao falar da Ciência Política.

Aqui irei tratar, a partir de pesquisa documental e bibliográfica, das remoções forçadas e relativamente pouco conhecidas ou investigadas que se

\footnotetext{
2 É preciso ter em conta que o livro História dos índios no Brasil foi publicado no início da década de 1990, quando ainda não estava acessível parte da documentação que se disponibiliza atualmente. Embora não haja no referido compêndio nenhum artigo dedicado exclusivamente a tratar da questão indígena no período militar, consta um no qual se trata da gestão do Serviço de Proteção aos Índios (SPI), cf. Souza Lima (1992). Acaba sendo inevitável notar que o próprio SPI teve inúmeros (dez) diretores militares, desde a sua fundação com o Marechal Rondon em 1910 (idem:159).
} 
deram no período militar, particularmente em seu período mais cruento, na década de 1970. Não são poucas as populações removidas e algumas delas ensaiaram fazer o retorno às suas terras originárias. De todo modo, irei tratar aqui um pouco mais detidamente de três casos que me parecem emblemáticos da violência perpetrada em décadas recentes. Dois deles dizem respeito grupos indígenas que eram então recém-contatados; o terceiro diz respeito a um grupo contatado há muito tempo, mas o que não lhes conferiu qualquer prerrogativa para permanecer onde estava. São os casos dos Xetá, dos Tapayuna e dos Ofaié, o primeiro falante de uma língua tupi-guarani e os dois últimos falantes de línguas do tronco Macro-Jê. Os três - localizados em diferentes estados brasileiros - Paraná, Mato Grosso e Mato Grosso do Sul - estão separados por centenas de quilômetros e inúmeras diferenças em suas histórias particulares, mas com a coincidência da remoção forçada de suas terras. Sem desconhecer outros deslocamentos do mesmo tipo no período militar, cabe indicar que foram também removidos os Kaiabi, os Guarani de diversas parcialidades (Kaiowá, Avá-Guarani, particularmente) os Nambiquara, os Waimiri-Atroari e os Parakanã, para mencionarmos apenas alguns. Cabe dizer ainda que, previsivelmente, não serei exaustiva, dado que começo apenas agora a me familiarizar à temática, que, ao que tudo indica, exigirá ainda mais tempo e maiores esforços de investigação, pois a documentação não só é bastante volumosa como também o acesso nem sempre é facilitado. Antes de adentrarmos cada um dos casos, noto que os deslocamentos forçados de grupos indígenas não causaram maiores discussões ou reflexões públicas, possivelmente porque então era parte da ordem constituída a indiferença aos assuntos indígenas e a urgência do "progresso", isso sem falar do silêncio - em algumas situações, também forçado - quanto aos assuntos relativos às ações do Estado. Na porção centro-brasileira e amazônica do país, se indígenas havia pelo caminho, a ordem era rapidamente dispô-los ao que se chamava então de "integração", uma ficção que não deixou de produzir seus próprios efeitos. O lema "integrar para não entregar", menos que um jogo de palavras, supunha a expansão das frentes de colonização que, inevitavelmente, alcançavam os índios em duplo sentido.

\section{Cada vez mais longe: ensaios de desterro}

Parte da adesão de parcelas da população nacional a tais ideias de integração e expansão das fronteiras está registrada em documentos de Comissões Parlamentares de Inquérito que tiveram lugar no Congresso Nacional na década de 6o. Antes de me dedicar a detalhar um pouco mais o que se passou com os três povos indígenas anteriormente mencionados, cabe dizer que a adesão de parcela da população e dos indigenistas aos deslocamentos estão registradas em alguns documentos que pude consultar. Assim, consta no terceiro tomo do Relatório Figueiredo, no depoimento do indigenista José Maria da Gama Malcher, em 11 de junho de 1963, uma proposta elaborada pelo Secretário de Agricultura do Rio Grande do Sul, Manoel Vargas (filho de Getúlio Vargas), para remover uma população indígena - certamente kaingang localizada nos limites do estado. Manejando o linguajar etnocêntrico vigente no país, Gama Malcher diz ter ouvido de "Maneco", como era apelidado Manoel Vargas, o pedido para que se "tirasse os bugres porque não se poderia perder a quantidade enorme de pinheiros que existiam nas terras indígenas". A proposta 
sugeria deslocar os Kaingang de seus toldos para nada mais nada menos que o Mato Grosso! Não consta no Relatório Figueiredo o desfecho de solicitação tão absurda, mas é previsível que não tenha sido acolhida, o que não impediu, de todo modo, que a exploração dos pinheiros tenha se efetivado. Isso se depreende do fato de que o mesmo Relatório Figueiredo traz, em seus diversos tomos, informações sobre a exploração das florestas de araucária no sul do país, resultando em apropriações indébitas e em danos socioambientais vultosos.

Posteriormente, no relatório da CPI de 1968, que diz respeito aos Remanescentes Indígenas, encontrei uma outra solicitação de remoção de população indígena. Agora a solicitação se dá Brasil Central, não mais no sul do país, permitindo assim indicar como o problema não era localizado. Neste caso trata-se da solicitação do prefeito de Tocantínia, que sugeriu, em correspondência enviada ao Presidente da República, em janeiro de 1967 portanto, no início do mesmo ano em que foi extinto o SPI -, remover os Xerente das proximidades do município. A sugestão era que os enviasse para bem longe: supostamente para "outra região, onde tivessem condições mais vantajosas, como na Ilha do Bananal, Parque do Xingu, etc".

Considerando a localização atual dos Xerente, é possível imaginar que o prefeito

também não teve sua solicitação acolhida. Anos antes, em agosto de 1956, ainda um prefeito de Tocantínia e vários munícipes, já haviam encaminhado a $\mathrm{J}$. Kubistcheck uma "Representação" sobre os conflitos que os envolviam com os índios locais - neste documento não são mencionadas denominações étnicas -, e arrolavam tanto queixas sobre o uso do tingui (veneno de pesca), quanto supostos "roubos de gado, assaltos às roças, espancamento de civilizados e ameaças às vidas de nossos sertanejos pacatos”. Atemorizados, os signatários sugeriam então que fossem os índios removidos para terras "localizadas entre os municípios de Itacajá e Piacá”, pois, conforme argumentam, "aquela área é mais que suficiente para os que já aqui se acham e os de cá". Dada a ausência de denominações étnicas no documento, é difícil precisar a quais etnias se referem, mas parece razoável supor, tendo em conta a localização de populações indígenas atuais, que estivessem sugerindo a retirada dos "de cá", possivelmente Xerente, para viver junto ou próximos aos Krahô, os "de lá". O que sobressai nas situações documentadas é que o lugar de índio deve ser sempre longe e bem circunscrito: se estão no Sul, devem ser enviados para o Centro-Oeste. Se estão no Centro-Oeste, devem ir um tanto mais para o Norte. Em nenhuma situação deveriam adentrar as cidades3. É importante que não estejam por perto e que, bem distantes, se façam esforços para convencê-los do ideal de civilização que proclamam os signatários. Cito-os literalmente para preservar a força de suas palavras:

\footnotetext{
"não somos contra os índios. Lutamos sim contra esta transformação do índio em um elemento criminoso, e que se tornou o flagelo da nossa gente, um óbice para nossa economia e um entrave para nosso progresso. Queremos a sua integração como valor positivo, nos quadros da nossa Pátria”.
}

Não acrescentaram, mas sugeriam com a solicitação que "a integração como valor positivo" deveria ser alcançada longe deles próprios. Em resumo, é como se dissessem "quanto mais longe, melhor", o que revela a própria ficção,

\footnotetext{
${ }^{3}$ A presença dos índios em cidades, temática que ganhou interesse recente na antropologia, é bem antiga e extensamente registrada, como se pode depreender das visitas dos Kaingang a Curitiba a fim de encaminhar seus interesses junto ao presidente da província no séc. XIX, no Império, como o mostram os documentos analisados por Pedro Fortes (2014).
} 
como chamei, do ideal de integração, nem seus supostos defensores estavam dispostos a se engajarem nela. $O$ projeto de remoção dos índios, fazendo deles pessoas desterradas, era assumido sem maiores hesitações e revelava propriamente a realização de seu banimento.

\section{Idas e vindas: a cobiça por territórios indígenas e as remoções forçadas}

\section{O caso dos Xetá}

Os Xetás, último grupo indígena a ser contatado no Sul do Brasil, quase sucumbiram diante do avanço desenfreado da frente cafeeira sobre suas terras no noroeste paranaense em meados do século passado. Avanço que lhes custou suas vidas. Em uma década, 1950, foram reduzidos de aproximadamente 200250 pessoas para 50, de acordo com dados demográficos indicados por Loureiro Fernandes (cf. Fernandes, 1959:31 e 1960). Portanto, foram reduzidos em aproximadamente $75 \%$ em um intervalo de 10 anos. Tendo em conta dados demográficos atuais, transcorridos sessenta e cinco anos a população ainda não alcança as cifras anteriores, dado que estão estimados em 160 pessoas, que vivem ainda em territórios alheios, como displaced persons. Seu território na Serra dos Dourados (noroeste do Paraná) resta apenas identificado e contestado. Seu efetivo reconhecimento e homologação não parece previsto para o futuro próximo.

Apesar da consolidação do contato tardio com os brancos, datado de meados do século passado, existem informações esparsas sobre os Xetá desde a metade do século XIX, como demonstram os textos reunidos na coleção Os Xetá no vale do rio Ivaí 1840-1920 (Mota, 2013). Os Xetá4 estavam então localizados nas imediações da Serra dos Dourados, instalados na margem esquerda do rio Ivaí, afluente do rio Paraná, onde delimita a fronteira dos estados do Paraná e do atual Mato Grosso do Sul. Vivendo da caça e da coleta, pequenos grupos perambulavam e dispunham seus acampamentos por uma extensa região.

Foi apenas na metade do século passado, quando a frente cafeeira se deslocou do norte para noroeste do estado do Paraná, pressionando o território por onde os pequenos grupos perambulavam, que o contato dos Xetá com os brancos se consolidou e tornou-se irreversível. O projeto varguista de "Marcha para o Oeste", fazendo avançar a fronteira agrícola da cafeicultura, encerrou qualquer possibilidade de os Xetá darem continuidade à fuga que empreendiam há algum tempo com relativo sucesso.

Ainda hoje o fato de os Xetá terem conseguido ocultar-se por tanto tempo surpreende, sobretudo quando se considera que o grupo indígena mais próximo, os Kaingang, têm um contato que recua ao final do século XVIII. E na outra margem do rio Paraná, do lado sul-matogrossense, os Ofaié (Dutra, 2004), também um grupo caçador-coletor, foram contatados aproximadamente cinquenta anos antes, no início do século XX. Entre dois grupos falantes de línguas do tronco Macro-Jê - os Kaingang e os Ofaié - os Xetá viveram em refúgio, obtendo relativo sucesso, até serem alcançados pela leva de novos colonizadores.

\footnotetext{
${ }^{4}$ Desde as primeiras ocorrências do grupo na literatura, persistem variações na expressão gráfica do nome daqueles índios que ora são grafados como Hetá, ora como Xetá, Setá, Chetá e Aré.
} 
Extremamente móveis, entre o final da década de 1940 e início de 1950, os Xetá foram cercados pelos brancos que avançavam sobre suas terras e então, pouco a pouco, pequenos agrupamentos foram aproximando-se das fazendas que começavam a se formar. Alguns documentos indicam que buscavam a aproximação para saciar a fome, pois cercados não conseguiam satisfatoriamente ter acesso aos recursos naturais, aos animais de caça e pesca.

Do que é possível saber, principalmente a partir de Kozak (s/d) foram os agrimensores da Companhia Colonizadora Suemitsu Miyamura Ltda, no final da década de 1940, no governo de Moysés Lupion (1947-1951), os primeiros a darem notícia do contato que se tornaria irreversível. Conforme relata Wladimir Kozak, foi Wismar Costa Lima Filho, funcionário da $7^{\text {a }}$ Inspetoria Regional do SPI quem recebeu, em julho de 1949, o comunicado de Agostinho Veronesi, agrimensor da Miyamura, sobre a presença dos Xetá nas imediações dos trabalhos da colonizadora.

Daí em diante organizam-se algumas expedições para contatar os Xetá, todas elas pouco planejadas, na avaliação de Kozak (s/d), resultando na consecutiva falta de sucesso e adiando o contato definitivo que, àquela altura, se tornava inevitável.

Já no governo de Bento Munhoz da Rocha (1951-54), a Companhia Colonizadora Suemitsu Miyamura Ltda foi substituída pela Companhia Brasileira de Imigração e Colonização (COBRIMCO), pertencente ao grupo Bradesco, conforme já indicado no Relatório da Comissão Nacional da Verdade.

Este pedaço da história se faz nebuloso e, de acordo com algumas fontes, a saída da Suemitsu Miyamura da Serra dos Dourados deveu-se a um acordo pouco divulgado que envolvia o governo Munhoz da Rocha, a COBRIMCO e o SPI, conforme foi afirmado em entrevista por Franz Licha, um ex-corretor de terras na região, no jornal Folha de Londrina, em 1994 (cf. Ubiratan, 1994).

Um filho de Suemitsu Miyamura, Hidemitsu Miyamura (2013), afirma que teria seu pai sido o primeiro empreendedor na região da Serra dos Dourados, em 1948, mas foi preterido a uma outra empresa - certamente a COBRIMCO em virtude de disputas políticas que envolviam Moysés Lupion e Bento Munhoz da Rocha, sendo o último, alinhado de Adhemar de Barros em São Paulo, vitorioso naquele momento.

Aqui torna-se inevitável destacar a excessiva proximidade entre as ações governamentais e as companhias de colonização no norte do Paraná, entre os interesses públicos e privados5. Segundo Gonçalves (1997), Bento Munhoz da Rocha, de uma família tradicional do Paraná, "foi desde sempre um intelectual visceralmente ligado à elite”. Logo após concluir seu mandato como governador, Munhoz da Rocha foi nomeado Ministro da Agricultura, em 1955. Em um de seus discursos enquanto deputado federal (1959-1962) fez uma defesa veemente do pioneirismo, justamente daqueles que estavam implicados na subtração da vida e do território dos Xetá. São suas palavras: "O pioneirismo significa, se não uma exigência de assistência do Governo, pelo menos atitude do Governo no sentido de que não atrapalhe a expansão pioneira" (Munhoz da Rocha apud Gonçalves, 1997).

De fato, tendo em conta a história dos Xetá fica claro que o governador foi fiel às suas palavras, não tentando obstar em nada o avanço dos pioneiros. Ao

\footnotetext{
${ }^{5}$ Cabe destacar, contudo, que as iniciativas em que se confundiam interesses públicos e privados não foi restrita ao governo de Munhoz da Rocha, podendo ser identificada igualmente nos governos Lupion: "A colonização do território paranaense foi basicamente efetuada pela inciativa privada que contava com o apoio do Estado. (...) Durante o governo Lupion as companhias colonizadoras adquiriram tal poder que chegaram a 'sobrepor-se' aos interesses do Estado" (Salles, 2004:69).
} 
contrário, ofereceu o suporte para que as companhias colonizadoras, especialmente a COBRIMCO, no território dos Xetá, agissem livremente.

A população xetá, acuada diante dos colonizadores, em menos de uma década sucumbiu diante da violência e de diversas mortes, decorrentes de doenças ou envenenamentos, raptos e desaparecimentos, sendo que todos esses termos se confundiam numa trama sinistra.

Assim, na documentação restam ainda vários desaparecimentos possíveis de serem identificados na menção a caminhões que se diz saírem da região da Serra dos Dourados carregados com diversos xetás, mas que iam adiante com destino incerto. O paradeiro desses xetás que foram dali retirados é completamente desconhecido: raptados e jamais retornados.

Por toda a década de 1950 os apelos para que se garantisse a demarcação de terras aos Xetá não foram ouvidos. Na década seguinte, com os militares tomando o poder, a situação em nada se altera. A condição desterrada dos Xetá simplesmente passou a ser dada como um fato consumado, como se os Xetá estivessem "rumo à extinção" e, portanto, sem que fosse preciso se comprometer com a reunião dos sobreviventes, alguns dos quais viveram anos sem saber da existência um dos outros, não sendo improvável que alguns restem ainda nessa condição.

Assim, é preciso notar aqui que no início da década de 1960 - em 30 de maio de 1961 - foi criado o Parque Nacional de Sete Quedes, em parte do qual reservou-se terras aos Xetá. No entanto, jamais se providenciou o retorno dos sobreviventes para o seu território e esses permaneceram dispersos em diferentes localidades. Passaram-se mais vinte anos e em 04 de junho de 1981 o Parque Nacional de Sete Quedas foi extinto pelo Decreto Presidencial 86.071 (Silva, 1998:210), no mandato do General João Batista Figueiredo. Em vinte anos, dezessete dos quais sob o domínio dos militares, não foram encaminhadas quaisquer providências para a reunião dos sobreviventes xetá no território que lhes foi destinado.

Ao fim e ao cabo, o Decreto de extinção do Parque Nacional de Sete Quedas encerra qualquer iniciativa de Estado para reunir e assistir os Xetá e põe fim também à própria paisagem natural, dado que o local conhecido como Sete Quedas foi inundado com o início do funcionamento da Usina Hidrelétrica de Itaipu, em 1982, que, na outra ponta, alcançava os índios Guarani6. Embora poucas vezes esse fato seja notado, com um único Decreto Presidencial foram subtraídos territórios de dois povos indígenas.

Da redemocratização do país até os dias de hoje a situação em pouco se alterou para os Xetá, que vivem ainda em territórios alheios, a maior parte na TI São Jerônimo da Serra, no município do mesmo nome, onde são minoritários entre os Kaingang e Guarani. De modo direto cumpre repetir as palavras do relatório da CNV: no período da ditadura militar os Xetá foram "jogados no esquecimento" (CNV, vol. 2, página 220).

Ainda sobre os Xetá, cabe apontar que hoje estão vivos seis sobreviventes - três homens e três mulheres - e mais de uma centena de descendentes que moram em diferentes locais, no meio urbano e rural: em Curitiba, em Douradina (PR), em Chapecó (SC) e nas Tis São Jerônimo da Serra e Marreca dos Índios, ambas no Paraná. A ideia de um coletivo surge sobretudo a partir dos descendentes, a maior parte reunida na TI São Jerônimo, em meio aos Kaingang e Guarani, com os quais são, aliás, aparentados dadas as diversas

\footnotetext{
${ }^{6}$ A história da construção da UHE Itaipu e seus impactos socioambientais são extensamente desenvolvidos na coletânea recém-publicada de D. Mamed, M. Caleiro e R. Bergold (2016).
} 
uniões interétnicas que possibilitaram a recomposição demográfica. Entre os descendentes resta a indignação dos mais jovens que logo que tiveram reconhecidas suas terras, a partir de um relatório de demarcação encomendado pela FUNAI, mas ainda não homologadas, foram acusados por descendentes dos colonizadores de serem "paraguaios" 7. Inevitável notar que, em tal contexto, "paraguaio" é não apenas usado como um termo pejorativo, mas também como índice de uma suposta condição "estrangeira" que foi também aventada à época do contato, conforme indicou Loureiro Fernandes, em 1961. Tem, portanto, longa duração.

A não demarcação das terras xetá, como se pode imaginar, esbarra também na questão do marco temporal, sobre o qual penso não ser necessário me alongar aqui, esse artifício jurídico impeditivo para o retorno de tantos povos às suas terras originárias8.

\section{O caso dos Tapayuna}

Um dos trabalhos mais atentos à perspectiva indígena sobre os efeitos das ações implementadas pelos militares - embora não tenha sido redigido com este propósito - é a dissertação de mestrado em Antropologia, defendida na UnB, de Daniela Lima (2012). Na dissertação é exposta a trágica história dos Tapayuna (povo de língua jê), localizados nas imediações da margem esquerda do rio Arinos, no Mato Grosso, e transferidos para o Parque Nacional do Xingu, para morar com os Kisedje (então Suyá) após a morte da maior parte de sua população como consequência da efetivação do contato com os brancos entre os anos 50 e 60. A autora, em dois capítulos de seu trabalho, recupera as lembranças de duas velhas tapayuna (uma moradora entre os Kisedje e outra entre os Kayapó) sobre os eventos do contato e nelas sobressaem cenas fortes: índios envenenados por arsênico misturado ao açúcar e, mais tarde, pela ingestão de carne de anta contaminada que lhes foi oferecida, crianças tentando amamentar nos seios de suas mães mortas e, como era comum no descuidado do período, muitas pessoas adoentadas, gripadas e logo mortas, infectadas pelos brancos que os alcançaram. Na dissertação, Lima (2012) intercala a fala das mulheres com imagens publicadas em revistas da época, tornando o enredo ainda mais trágico: muitas fotos dos recém-descobertos Beiços-de-pau, como eram conhecidos pelos brancos os Tapayuna, e nenhum socorro imediato! Como se fosse inevitável uma tragédia extensamente fotografada!

No final da década de 60, com a estabilização do contato, foram-lhes reservadas terras no décimo terceiro paralelo, na margem esquerda do Rio Arinos, conforme estabelecido no Decreto 63.368 de 8 de outubro de 1968. Sem que fossem mantidos em seu território, a área foi extinta oito anos depois, em o9 de junho de 1976, conforme consta do Decreto 77.790, assinada pelo General Ernesto Geisel.

\footnotetext{
7 A acusação de serem os Xetá índios “paraguaios” se repete também com outros povos indígenas, como é o caso dos Mbyá-Guarani em Santa Catarina e dos Guarani, Kaiowá e Terena no Mato Grosso do Sul. Em quaisquer contextos, o que está em disputa são suas terras.

${ }^{8}$ Cabem apenas algumas breves palavras: o marco temporal, conforme estabelecido pelo Superior Tribunal Federal, exige a presença efetiva do grupo indígena na terra reivindicada em o5 de outubro de 1988, data da promulgação da Constituição, contrariando então a comprovação de sua posse imemorial, como prevê a mesma Constituição. Um dos principais problemas da fixação do marco temporal é que desconsidera o esbulho e violência do processo de colonização como os causadores da ausência do grupo da terra pleiteada na data arbitrariamente fixada, como é o caso aqui tanto dos Xetá quanto dos Tapayuna. Para uma crítica bastante robusta ao Marco Temporal, ver o parecer do jurista José Afonso da Silva (2015).
} 
A investigação de quem foram as pessoas que restaram como proprietárias do território Tapayuna me parece merecer atenção, pois não é de fácil entendimento o recuo na decisão de demarcar a área. Torna-se ainda mais difícil o entendimento deste quadro se se considera que aproximadamente 40 sobreviventes tapayuna foram removidos, por avião, para o PIX em 1971, sendo que tiveram suas terras demarcadas três anos antes. Segundo Lima, o deslocamento dos sobreviventes foi "uma decisão tomada à revelia dos índios, com base na proximidade [dos Kisedje] em termos culturais e linguísticos" (Lima, 2012:09). A pergunta que faço é bastante simples: por que deslocá-los se havia terras para reuni-los? A quais interesses responde a decisão de retroceder na demarcação é o que resta saber.

$\mathrm{Na}$ chegada ao PIX, os Tapayuna foram recepcionados pelos Kisedjê, os quais, após terem sofrido inúmeras influências alto-xinguanas, viram neles a oportunidade de retomarem suas "antigas" tradições, dado que não tinham experimentado os mesmos processos históricos. De uma certa forma, dadas as semelhanças linguísticas e culturais entre ambos os grupos, era como se os segundos vissem os primeiros como seus modelos pretéritos ou algo do tipo. Nas palavras de Seeger (2015:258), "a chegada do novo grupo desencadeou uma renascença cultural kisedjê. Os dois grupos investigaram como cada um realizava as cerimônias que tinham em comum e partilharam experiências, cantos e ideias”. Pouco tempo depois, contudo, desavenças entre membros de lado a lado resultaram na saída de parte dos Tapayuna para viverem próximos dos Mebengokre.9

Das informações possíveis de se obter agora, sabe-se que os Tapayuna, hoje dispersos nos territórios dos Kisedjê e dos Kayapó, com os quais se afinizaram, estão planejando reivindicar a volta às suas terras tradicionais (informação pessoal, Lima, 2015). Ou seja, consideram a possibilidade de fazer o caminho de volta.

\section{O caso dos Ofaié}

Um outro deslocamento compulsório que se deu no período militar, e que me parece merecedor de atenção, é aquele referente aos Ofayé-Xavante, doravante Ofaié, da família linguística ofayé (tronco Macro Jê). Os Ofaié, diferente dos Xetá e dos Tapayuna, tinham um contato bem mais antigo com os brancos no período militar (1964-1985), de aproximadamente um século, e foram igualmente removidos de sua área de ocupação tradicional, à beira da margem direita do rio Paraná, entre a foz do rio Sucuriú até as nascentes do Ivinhema, no atual estado do Mato Grosso do Sul10. O contato dos Ofaié com os brancos recua ao início do século XX, existindo sobre eles anotações de Marechal Cândido Rondon e de Curt Nimuendajú (1993). Quando Marechal Rondon os visitou, estimou a população total em 2 mil pessoas, número bastante avantajado, indicativo da tragédia que os abateu se tivermos em consideração que Borgonha (2006:08), encontrou apenas 69 pessoas quando realizou seu trabalho de campo nos primeiros anos da década passada. Apesar da acentuada redução demográfica, os Ofaié ficaram mais conhecidos na

\footnotetext{
${ }^{9}$ Daniela Batista Lima, após ter realizado seu mestrado com os Tapayuna moradores da aldeia Wawi, dos Kisedjê, dá continuidade à sua pesquisa, agora em nível de doutoramento, com os Tapayuna que foram viver entre os Mebengokre (informação pessoal, 2015).

${ }^{10}$ Não é demais lembrar aqui que o Mato Grosso do Sul tem a segunda maior população indígena do país, mas é marcado pela exiguidade dos territórios indígenas demarcados e pelos problemas que enfrentam em decorrência, entre outras coisas, da superlotação de suas terras.
} 
literatura antropológica por intermédio de Claude Lévi-Strauss, servindo-se de um artigo de Darcy Ribeiro (1951), que os visitou no final da década de 1940 e teve acesso ao mito da origem do mel dos Ofaié, o qual é extensamente evocado no segundo volume das Mitológicas, o Do mel às cinzas.

Curt Nimuendajú encontrou alguns Ofaié aprisionados em Vacaria (sul do Mato Grosso) no início do século XX e registrou a brutalidade dos brancos:

\footnotetext{
"...os seus perversos donos tornaram os inventores engenhosos a fim de atormentálos. Divertiram-se por exemplo amarrando alguns índios recém-pegados nas pontas de um laço e disparando tiros no meio deles. Assustados pela descarga, os índios procuraram fugir para todos os lados, mas logo que o laço se esticou, caíram e arrastaram um ao outro pelo chão, debaixo da gargalhada dos sertanejos" (Nimuendajú, 93:103).
}

Acossados pela frente de expansão pastoril nos primeiros anos do século XX, os sobreviventes ofaié, já em 1978 (Dutra, 2005) - no período militar, portanto -, foram transferidos de Brasilândia, cidade formada dentro de seu território tradicional (localizado no sudeste do MS), para a Serra da Bodoquena, nas proximidades de Porto Murtinho, em área Kadiwéu localizados no noroeste do mesmo estado. Mais de 700 quilômetros separam os dois locais. Oito anos após, em 1983, distantes de seu território tradicional, empreenderam a pé o retorno, pois não se adaptaram em terras alheias e, ao mesmo tempo, viram-se cercados de conflitos que envolviam índios Kadiwéu, Terena e fazendeiros em torno de contratos de arrendamento.

O deslocamento do grupo em 1978 (um ano, portanto, após a divisão do estado do Mato Grosso), segundo o que se tem registrado, foi realizado pela FUNAI e, em certa medida, patrocinado por políticos e fazendeiros locais, interessados em suas terras. De acordo com a fala do cacique José de Souza, reproduzida na dissertação de mestrado de Borgonha (2006:56-7):

\begin{abstract}
"O povo Ofaié foi deslocado daqui da região de Brasilândia, ou melhor, daqui do município de Brasilândia até a Reserva Indígena Kadiwéu, no município de Porto Mortinho. Bom, nosso deslocamento foi organizado através de alguns políticos locais e também, os fazendeiros, que estavam interessados na nossa aldeia, na nossa terra. Como na época era o tempo da ditadura, época militar, época que eles mandavam, né, então, a gente fomos deslocados, porque se a gente resistisse, com certeza, a gente seria forçado e colocado no carro, no caminhão a força, pra ser deslocado para a Bodoquena, na Reserva Indígena Kadiwéu”.
\end{abstract}

No laudo pericial Ofayé-Xavante, respondido pelo perito, o arqueólogo Gilson Rodolfo Martins (s/d), da UFMS, repete-se, certamente em outros termos, a mesma versão, conforme se pode ver na resposta ao quesito:

\footnotetext{
"Os índios foram desalojados à força?: Não (...) a transferência foi promovida pela FUNAI. Provavelmente os índios a aceitaram por não terem outra opção $e$ equivocados sobre as condições que lhes foram oferecidas, pois do contrário não teriam retornado para Brasilândia assim que tiveram oportunidade (1986)".
}

\title{
Tecnologia do contato, das remoções e as des-demarcações
}

São bastante importantes as informações que são apresentadas nas etnografias e estudos históricos sobre os Xetá (Silva, 1998), os Tapayuna (Lima, 2012) e os Ofaié (Borgonha, 2006 e Dutra, 2005), mostrando como os deslocamentos compulsórios foram impostos a diferentes grupos, em diferentes localidades e com diversas experiências de contato, antigas ou recentes. Em comum aos três casos acaba se revelando o que é possível chamar de "tecnologia 
do contato e das remoções", em que se sobressaem não as famosas miçangas, machados e espelhos de outrora, mas sim suas ações determinadas de extermínio e redução, com o envenenamento dos recém-contatados - como nos casos dos Xetá e dos Tapayuna - e do deslocamento forçado de seus territórios - como nos três casos, variando apenas o meio de transporte: caminhões para Xetá e Ofaié e avião para os Tapayuna.

Apesar do mal-estar que a própria imagem provoca, é preciso chamar a atenção para o fato de que a rendição dos índios chegou mesmo a ser ostentada, como foi o caso dos Xetá, segundo um corretor de terras, Franz Licha, afirmou para um jornalista da Folha de Londrina: "os xetás viajaram numa noite fria de geada, depois de desfilarem pelas ruas de Cruzeiro do Oeste vestindo camisas da COBRIMCO, uma colonizadora do grupo Bradesco".

Outros elementos adensam-se às estratégias empregadas e que resultaram no estabelecimento dos indígenas fora de seu território de origem. Tanto os Xetá quanto os Tapayuna tiveram territórios demarcados na década de 60, para, alguns anos depois, no período militar, ser desprezada a alternativa de mantêlos em seu território tradicional. No caso dos Xetá, foi inundado o território que era parte do Parque Nacional de Sete Quedas; no caso dos Tapayuna suas terras foram praticamente confiscadas, sem que possa ainda estabelecer qual foi seu destino. Em ambos os casos é como se pudéssemos falar que os Xetá e Tapayuna tiveram suas terras "des-demarcadas", dado que o poder federal retrocedeu nas demarcações feitas, jamais permitindo que os indígenas nelas vivessem. No primeiro caso, dos Xetá, inundando o território demarcado; no outro, dos Tapayuna, as terras demarcadas foram praticamente confiscadas para, na sequência, serem repassadas à iniciativa privada.11

A realocação dos grupos em determinadas locais chama também a atenção. Neste caso, os Tapayuna foram deslocados para o PIX, a oeste de seu território tradicional; enquanto os Ofaié foram deslocados para noroeste, em terras Kadiwéu nas proximidades da Serra da Bodoquena (MS). Como é sabido, a TI Kadiwéu lhes foi concedida logo após a Guerra do Paraguai, e, ao que consta (Pechincha, 1999) inicialmente foi pensada como uma "recompensa" pelos esforços de guerra. Extensa para as medidas que vigoram no MS, para lá foram deslocados os Ofaié liberando o território na margem direito do rio Paraná para empreendimentos agrícolas - pois, segundo vigorava no órgão tutor a ideia de que "os Kadiwéu possuíam muitas terras" (Silva, 2004:84), donde seria justificável a transferência de outros grupos para lá. Enquanto os Tapayuna ainda planejam voltar, os Ofaié não suportaram ficar longe e empreenderam o retorno a pé para seu próprio território, restando hoje em uma área de aproximadamente 600 hectares, nas cercanias de Brasilândia, nas proximidades da margem direita do rio Paraná.

Chama a atenção que, como indicado antes, a extensão das terras kadiwéu parecia justificar, no entendimento do órgão tutor, a transferência de outros grupos para lá - como se passou com os Ofaié, alguns Guarani e Terena. Não deve ser excessivo especular que, mais a oeste, o PIX parecia ocupar esse mesmo lugar, tendo para seu perímetro transferido outros grupos indígenas, como é o caso dos Tapayuna e dos Kaiabi, além dos Panará e dos Ikpeng.

\footnotetext{
${ }^{11}$ Note-se aqui que essa possibilidade - a transferência das terras tapayuna para a iniciativa privada - é apenas uma especulação, dado que não pude ainda consultar as certidões negativa da cidade de Diamantino (MT). Iniciei tratativas com o Setor de Documentação da FUNAI (SEDOC/FUNAI) para obter acesso às certidões negativas no início de maio de 2015, mas até agora não obtive qualquer resposta definitiva, as tratativas simplesmente continuam.
} 
O contexto político em que se produziu a mortandade e a expropriação das terras dos grupos aqui tratados, faz-se ainda mais notável quando se observa que a Convenção 107, de 05 de junho de 195712, da Organização Internacional do Trabalho foi ratificada pelo Brasil. Em tal Resolução, concernente às Populações Indígenas e Tribais, estava previsto em seu $12^{\circ}$ Artigo:

\begin{abstract}
1. As populações interessadas não deverão ser deslocadas de seus territórios habituais sem seu livre consentimento, a não ser de conformidade com a legislação nacional, por motivos que visem à segurança nacional, no interesse do desenvolvimento econômico do país ou no interesse da saúde de tais populações.

2. Quando, em tais casos, se impuser um deslocamento a título excepcional, os interessados receberão terras de qualidade ao menos igual à das que ocupavam anteriormente e que lhes permitam satisfazer suas necessidades atuais e assegurar seu desenvolvimento futuro. Quando houver possibilidade de encontrar outra ocupação ou os interessados preferirem receber uma indenização em espécie ou em dinheiro, serão assim indenizados com as devidas garantias.

3. As pessoas assim deslocadas deverão ser integralmente indenizadas por toda perda ou dano por elas sofrido em consequência de tal deslocamento.
\end{abstract}

Ou seja, previa-se tudo o que não foi realizado nos casos aqui tratados. Não se deve perder de vista que no ano de 1957, da ratificação da Resolução 107 da OIT, estava em curso o ápice do genocídio dos Xetá e dos Tapayuna, o qual teve continuidade nos anos que se seguiram. Por toda a década de 1960, estabelecida a ditadura militar, o projeto de poder implantava-se pela força, avançando sobre as terras dos índios. Assim, as práticas que se colocaram em funcionamento vão na contramão de tudo o que estava previsto na Resolução 107: Xetá, Tapayuna e Ofaié foram violentamente deslocados de seu território habitual; não lhes foram demarcadas terras em qualquer outro local; sequer se cogitou que devessem ser indenizados por todas as perdas e danos.

Tais grupos, sem falar de outros, sofreram violências de toda ordem. Diante do que foi até aqui exposto, quando se aprecia com algum detalhamento o contexto anterior, pode-se sem receios examinar o Decreto 4388/o2, de 25 de setembro de 2002, e não haverá outra conclusão a se tirar a não ser que Crimes de Genocídio (Art. $6^{\circ}$ ) e Crimes contra a Humanidade (Art. $7^{\circ}$ ) tiveram lugar na história dos Xetá e Tapayuna, especialmente nas décadas de 50 e 60: crianças e adultos foram mortos, envenenados, violentados, raptados e deslocados.

$* * * * *$

É certo que as remoções forçadas se constituíram a partir do interesse em liberar as terras para colonização. Não se deve perder de vista, de qualquer maneira, que o ideal de "integração aos valores da Pátria" foi encarado pelo SPI, especialmente a partir da década de 1940, conforme se pode concluir da leitura dos Boletins Internos, na tentativa de conversão dos índios em ruralistas13. Para que tal afirmação não soe como um exagero, convém lembrar o que consta do próprio Regimento do SPI: “q) combater o nomadismo e fixar as tribos, despertando o gôsto do índio para a agricultura e indústrias rurais $\mathrm{e}$

\footnotetext{
12 Substituída pela Convenção 169, de 1989.

${ }^{13}$ A afirmação de que se tentava transformar os índios em ruralistas pode parecer enfática demais, mas é menos que isso. Qualquer um pode chegar à mesma conclusão dedicando-se a explorar os boletins de notícia publicados pelo então órgão tutor que, por toda a década de 1940, 50 e 60, trazem balanços da quantidade de cabeças de bovinos, caprinos e suínos nos Postos, dos resultados de projetos agrícolas, das comemorações ufanistas do Dia do Índio, dos resultados escolares e por aí vai. Nos vários Boletins repete-se tediosamente a mesma contabilidade dos animais dos postos, como se da fazenda fossem. Nula atenção é dada à diversidade das populações que os servidores atendem. Em um artigo de Nötzold e Bringmann (2013) são também disponibilizadas informações e reflexões que sustentam a afirmação.
} 
assegurando, pelo incremento das mesmas e da pecuária, uma base sólida à vida econômica do índio”.

Uma tal concepção só pode ser entendida se se atenta à concepção de terra que norteava o SPI desde seus primórdios e que foi posta em prática especialmente nas terras indígenas localizadas no sul e sudeste do país. Antes de qualquer coisa, do atendimento e acolhimento aos índios, era dever fazer as terras serem produtivas e naqueles tempos os agentes do SPI apenas conseguiam imaginar a produtividade da terra vinculando-a aos fazeres agrários que excedessem a subsistência: à criação de animais e à produção agrícola, ainda que, em alguns casos, às custas de espúrios arrendamentos - conforme documenta o já citado Relatório Figueiredo. Tanto pior é deparar-se com a contabilidade alardeada nos Boletins do SPI se lembrarmos que a tentativa de converter os índios em ruralistas - ou dos agentes estatais se tornarem ruralistas a partir da exploração dos territórios e da mão-de-obra indígena - é usada hoje em dia contra eles próprios. Como escreveu D. Gallois (2004), na atualidade, "o engajamento dos índios em atividades antes monopolizadas pelos não-índios ou sua articulação à economia regional" via de regra opera contra eles, como se índios não mais fossem, como se tivessem perdido suas tradições.

Aproximando-me do fim, retomo uma antiga afirmação de A. Seeger e E. Viveiros de Castro, de 1979, sobre as formas de ocupação das terras indígenas. Escreveram os autores:

\begin{abstract}
“(...) Vários grupos indígenas dependem, na construção de sua identidade tribal distintiva, de uma relação mitológica com um território, sítio da criação do mundo, memória tribal, mapa do cosmos - como é o caso dos grupos do Alto Xingu e do Rio Negro. Via de regra, são os grupos que praticam formas de subsistência mais sedentárias os que apresentam tal enraizamento simbólico com seu território. Outros, como os Gê e os Yanomami, por estarem em processo de expansão (...) e por se apoiarem em adaptações mais móveis ao meio ambiente, não parecem definir sua identidade em relação a uma geografia determinada. Sua organização social, por assim dizer, se apresenta em termos conceituais, antes que geográficos. Estas diferenças são básicas, pois o deslocamento dos grupos do primeiro tipo de seus territórios tradicionais tem implicações mais que puramente econômicas”. (1979:104)
\end{abstract}

A essa altura, suponho que os autores de tal afirmação, reconhecidos pela qualificada contribuição à Etnologia das terras baixas sul-americanas, não a repetiriam, dada a extensa produção sobre povos caçadores coletores que se avolumou de lá para cá (Ingold, 2000; Fausto; 2001; Garcia, 2012). A afirmação de que "formas de subsistência mais sedentárias" implicam um maior enraizamento simbólico ao território, parece difícil de ser sustentada tanto se nos dedicamos a tal literatura quanto se nos atemos detalhadamente para as remoções forçadas que lhes foram impostas em anos recentes como consta dos casos que antes abordei. Penso aqui particularmente no caso dos Ofaié, caçadores e coletores, localizados no alto Paraná, e que foram, como vimos antes, no período militar deslocados para junto dos Kadiwéu, ao noroeste, a aproximadamente 600 quilômetros de distância e fizeram o retorno a seu território a pé oito anos depois! Os Ofaié, como é sabido, era um desses grupos que se apoiava em "adaptações mais móveis ao meio ambiente", mas que não se rendeu a viver longe de seu território, tanto pior porque foram tidos como "intrusos" no outro lugar. Isso para não falar dos também mencionados Kaiabi ou dos planos recentes dos Tapayuna e Xetá de retornarem para suas terras originárias - ambos também forçosamente deslocados para viverem entre seus inimigos pretéritos.

A mobilidade permanente por amplas extensões de terra - ainda que em refúgio, dado o avanço das frentes de expansão -, não parece supor algum tipo 
de desenraizamento crônico. Poder-se-ia mesmo imaginar o contrário: tendo periodicamente palmilhado o território em toda sua extensão, em companhia dos seus, os deslocamentos poderiam fazê-los um tanto mais miméticos - no sentido de afeitos e mais conhecedores - ao próprio entorno, também com implicações que ultrapassam a economia.

De qualquer maneira, é preciso matizar e desenvolver um tanto mais a ideia apresentada no excerto acima, pois nos casos aqui abordados, tento, por um lado, explorar o contexto sócio histórico de grupos que foram forçosa e violentamente removidos de suas terras - expropriados propriamente falando , não estou tratando de deslocamentos livres em territórios desimpedidos. Por outro lado, é ainda preciso notar que o "enraizamento" - e os retornos empreendidos e desejados - pelos seus antigos lugares não deve ignorar a violência com que deles foram retirados, e que pode ter resultado em um efeito imprevisto: reforçado a identificação com "uma geografia determinada", com um lugar ao qual se deseja voltar. Aqui faço menção então a sentimentos que acabam sendo aflorados pelo próprio desterro entre sobreviventes e descendentes que vivem em situação de exílio (Said, 2003). Ao fim e ao cabo, se caçadores coletores são mais ou menos enraizados às suas terras, acabará sempre restando como uma hipótese sem solução de averiguação - tanto pior no contexto contemporâneo onde toda terra já foi cobiçada, invadida e, se ainda não foi, está em vias de ser dilapidada. Por fim, retornando a Seeger e Viveiros de Castro (1979), se outrora prevalecia uma pluralidade de definições de território (e de terra), o próprio processo colonial deu margem à "uniformização" de uma única concepção entre os diversos grupos indígenas, subtraindo então a riqueza de suas conceituações particulares, que passam a se aproximar da noção ocidental de propriedade, tal como prevista em nosso arcabouço jurídico (idem:106).14

Para encerrar, resta pôr em relevo que as concepções de uso da terra envolvidas nos três grupos sumarizados acima - e certamente em outros - é seguramente diversa daquela que inspirava e orientava os órgãos tutelares que os alcançaram e que violentamente agiam para retirá-los do caminho - fosse o SPI, fosse a FUNAI, a depender do caso e do período específico. A concepção de uso do território dos indígenas - fossem sedentários ou não - e dos agentes estatais ancorava-se em diferentes entendimentos do que vem a ser produção: para os primeiros, produção de pessoas como mostra fartamente a literatura etnológica das terras baixas nas últimas décadas (Da Matta, Seeger e Viveiros de Castro, 1987; Lea, 2012); para os segundos, produção de excedentes de alimentos a serem comercializados para garantir uma suposta autossuficiência dos postos indígenas - sem mencionar a possibilidade de que se punha em operação interesses escusos, como também foi fartamente documentado no Relatório Figueiredo.

Independentemente de qualquer desconfiança que inevitavelmente possa prevalecer, os agentes estatais não se dedicavam a buscar entender o que poderia ser compreendido como excedente entre pessoas que não havia muito tempo construíam sua autossuficiência por outros meios e sem ter de dispor de sua mão-de-obra violentamente em proveito de outrem. Aparentemente deslocadas no tempo, as ideias ocidentais - para não dizer propriamente

\footnotetext{
${ }^{14}$ Neste sentido, da "uniformização" da concepção de terra e território indicada por Seeger e Viveiros de Castro (1979), relembro uma situação vivida em campo, a partir da pesquisa anteriormente realizada entre os Katukina de língua pano, localizados no Acre, quando os velhos fizeram jovens lideranças retrocederem da decisão de permitir que algumas famílias arara, também de língua pano, fixassem residência entre eles. O argumento era inequívoco: os Arara "já tinham suas terras também demarcadas", não cabia, portanto, admiti-los nas suas (Lima, 2011).
} 
brancas e (ainda) estatais - de produção e excedente permanecem assombrando essas mesmas populações.

\section{Bibliografia}

BORGONHA, Mirtes. História e etnografia Ofayé: estudo sobre um grupo indígena do centrooeste brasileiro. Dissertação de mestrado (Antropologia Social): PPGAS/UFSC, 2006.

CARNEIRO DA CUNHA, Manuela. História dos índios no Brasil. São Paulo: Cia das Letras, 1992.

CASTRO, Celso e CUNHA, Olívia M. "Quando o campo é o arquivo", Estudos históricos, 36, 2005: 3-5.

DA MATTA, R.; SEEGER, A. \& VIVEIROS DE CASTRO, E. "A noção de pessoa nas sociedades indígenas brasileiras". In: Oliveira Filho, João Pacheco. Sociedades Indígenas e Indigenismo no Brasil. Rio de Janeiro: Marco Zero/UFRJ, 1987: pp. 7-41.

DAVIS, Shelton. Vítimas do milagre. O desenvolvimento e os índios do Brasil. Rio de Janeiro: Zahar Editores, 1978.

DUTRA, Carlos Alberto. O território ofaié pelos caminhos da história. Reencontro e trajetória de um povo. Dissertação de Mestrado (História), UFMS (campus de Dourados), 2004.

FAUSTO, Carlos. Inimigos fiéis. São Paulo: Edusp, 2001.

Folha de Londrina. A revolta marcada por uma cruz. 06 de maio. 1994.

FORTES, Pedro Henrique Ribas. Entre a política indígena e a política indigenista: um estudo sobre as relações políticas entre índios e não índios em Curitiba no séc. XIX. Dissertação de mestrado (Antropologia): UFPR, 2014.

HECK, Egon. Os índios e a caserna - políticas indigenistas dos governos militares - 1964/1985. Dissertação de mestrado (Ciência Política): UNICAMP, 1996.

GALLOIS, Dominique. "Terras ocupadas? Territórios? Territorialidades". In. Fany Ricardo. Terras indígenas e unidades de conservação da natureza: o desafio das sobreposições. São Paulo: ISA, 2004.

GARCIA, Uirá. "Ka'a Watá, 'andar na floresta': caça e território em um grupo Tupi da Amazônia”. Mediações, 17 (1), 2012: 172-190.

GARFIELD, Seth. A luta indígena no coração do Brasil. Política Indigenista. A marcha para o oeste os índios xavante (1937-1988). São Paulo: Editora Unesp 2007. 
INGOLD, Tim. The perception on environment: essays of livelihood, dwelling and skill. London/New York: Routledge, 2000.

LEA, Vanessa. Riquezas tangíveis de pessoas partíveis. São Paulo: Edusp, 2012.

LIMA, Antonio Carlos. "O governo dos índios sob a gestão do SPI”. In: Carneiro da Cunha, Manuela. História dos índios no Brasil. São Paulo: Cia das Letras, 1992, pp. 155-172.

LIMA, Daniela B. 'Vamos amansar uns brancos para pegar as coisas'. Elementos da etnohistória Kajkhwakratxi-jê (Tapayuna). Dissertação de mestrado (Antropologia Social), Unb, 2012.

LIMA, Edilene Coffaci. "Quem são os Noke Kuin? Acerca das transformações dos Katukina (Pano)". In: Edilene Coffaci de Lima; Lorena Córdoba. (Org.). Os outros dos outros. Relações de alteridade na Etnologia Sul-Americana. Curitiba: Editora da UFPR, 2011, pp. 135-147.

MAMED, Danielle; CALEIRO, Manuel e BERGOLD, Raul. Os Avá-Guarani no Oeste do Paraná: (Re)Existência em Tekoha Guasu Guavira. Curitiba: Letra da lei, 2016.

MARTINS, Gilson Rodolfo. Laudo pericial Ofaié-Xavante, ms, (s/d).

MONTEIRO, John. Guia de fontes para a história indígena e do indigenismo em arquivos brasileiros. Acervo das capitais. Rio Branco: NHII/USP/FAPESP, 1994.

NIMUENDAJÚ, Curt. Etnografia e indigenismo. Sobre os Kaingang, os OfaiéXavante e os índios do Pará. Campinas: Editora da Unicamp 1993.

NÖTZOLD, Ana Lúcia e BRINGMANN, Sandor F. "O Serviço de Proteção aos Índios e os projetos de desenvolvimento dos Postos Indígenas: o Programa Pecuário e a Campanha do Trigo entre os Kaingang da IR7”, Revista Brasileira de História \& Ciências Sociais, v. 5, n.10, 2013, pp. 147-166.

OLIVEIRA, Frederico C. B. Quando resistir é habitar: lutas pela afirmação territorial dos Kaiabi no baixo Teles Pires. Brasília: Paralelo 15, 2012.

PECHINCHA, Mônica. "Kadiwéu", Povos Indígenas no Brasil. São Paulo, Instituto Socioambiental, 1999. Disponível a partir de goo.gl/jSG7Bc. Acesso em 17 de nov de 2016.

RIBEIRO, Darcy. "Notícia dos Ofaié-Chavante". Revista do Museu Paulista, n.s., v. 5. São Paulo, 1951.

Os índios e o civilização. A integração das populações indígenas no Brasil moderno. Petrópolis, Vozes, 1986

RODRIGUES, Patrícia Mendonça. Identificação e delimitação da Terra Indígena Kayabi - Portaria 1137/93. Funai, ms., 1994. 
SAID, Edward. Reflexões sobre o exílio e outros ensaios. São Paulo: Cia das Letras. 2003.

SEEGER, A. Por que cantam os Kisedjê. São Paulo: Cosac Naify, 2005.

SEEGER, A. e VIVEIROS DE CASTRO, E. Terras e territórios indígenas. Rio de Janeiro: Civilização Brasileira, 1979.

SILVA, Carmen Lúcia. Os Xetá: sobreviventes do extermínio. Florianópolis, UFSC, Dissertação de Mestrado em Antropologia Social, 1998.

SILVA, Fabíola e STUCHI, Francisco. "Evidências e significados da mobilidade territorial: a terra indígena kaiabi (Mato Grosso, Pará)". Amazônica 2 (1), 2010: 46-70.

SILVA, José Afonso. "Parecer". 2015. Disponível a partir de goo.gl/JXA2On . Consultado em 14 de nov de 2016.

SILVA, Giovani José. A construção física, social e simbólica da Reserva Indígena Kadiwéu (1899-1984): memória, identidade e história. Dissertação de Mestrado (História): UFMS (campus Dourados), 2004.

SOUZA LIMA, Antonio Carlos. "O governo dos índios sob a gestão do SPI". In. Carneiro da Cunha, Manuela (org.). História dos índios no Brasil. São Paulo: Cia das Letras, 1992, pp. 155172.

\section{Recebido em 22/11/2016.} Aprovado em 28/11/2016. 